\title{
Prognosis of ampullary cancer based on immunohistochemical type and expression of osteopontin
}

\author{
Xiang-qian Zhao, Jia-hong Dong ${ }^{*}$, Wen-zhi Zhang and Zhe Liu
}

\begin{abstract}
Background: Ampullary cancer (AC) was classified as pancreatobiliary, intestinal, or other subtype based on the expression of cytokeratin 7 (CK7) and cytokeratin 20 (CK20). We aimed to explore the association of AC subtype with patient prognosis.

Methods: The relationship of AC subtype and expression of Osteopontin (OPN) with the prognosis of $120 \mathrm{AC}$ patients after pancreaticoduodenectomy was investigated.

Results: The patients had pancreatobiliary $\left(\mathrm{CK}^{+} / \mathrm{CK} 20^{-}, \mathrm{n}=24,20 \%\right)$, intestinal $\left(\mathrm{CK}^{-} / \mathrm{CK} 20^{+}, \mathrm{n}=29,24.2 \%\right)$ or other $\left(C K 7^{+} / C K 20^{+}\right.$or $\left.C K 7^{-} / C K 20^{-}, n=67,55.8 \%\right)$ subtypes of $A C$, and their median survival times were $23 \pm 4.2,38$ \pm 2.8 and $64 \pm 16.8$ months, respectively. The survival times of $64 \mathrm{OPN}^{-}$patients (53.3\%) and $56 \mathrm{OPN}^{+}$patients (46.7\%) were $69 \pm 18.4$ and $36 \pm 1.3$ months, respectively. There was no significant effect of AC subtype on survival of $\mathrm{OPN}^{-}$patients. For $\mathrm{OPN}^{+}$patients, those with pancreatobiliary AC had a shorter survival time (22 \pm 6.6 months) than those with intestinal $A C$ ( $37 \pm 1.4$ months, $p=0.041$ ), and other AC subtype (36 \pm 0.9 months, $p=0.010$ ); intestinal and other AC subtypes had similar survival times.
\end{abstract}

Conclusions: The prognosis of AC patients can be estimated based on immunohistochemical classification and OPN status.

Keywords: ampullary cancer, osteopontin, survival analysis, immunohistochemistry, classification, Cytokeratin 20, Cytokeratin 7

\section{Background}

Ampullary carcinoma (AC) is a relatively rare tumor of the hepatopancreatic ampulla that accounts for approximately $0.2 \%$ of gastrointestinal tract malignancies and $7 \%$ of periampullary carcinomas [1]. ACs have different anatomical origins. Kimura et al. initially classified AC as pancreatobiliary $\mathrm{AC}$ if it had papillary projections with scant fibrous cores and as intestinal AC if it resembled tubular adenocarcinoma of the stomach or colon [2]. Numerous studies have reported that intestinal AC is associated with a better prognosis than pancreatobiliary AC [1-5].

$\mathrm{AC}$ has also been classified based on immunohistochemical expression of cytokeratin 7 (CK7), Mucins and CDX2

\footnotetext{
* Correspondence: dongjh301@163.com

Hospital \& Institute of Hepatobiliary Surgery, Chinese PLA General Hospital, 28 Fuxing Road, Beijing 100853, China
}

[4,6-8] and HNF4 $\alpha$ [9]. However, the clinical significance and survival rates of $A C$ patients with these different immunohistochemical subtypes have not been definitely established.

Histologic classification and immunohistochemical characterization by cytokeratins are in good agreement [5]. Fischer et al. reported that the histological subtypes of $\mathrm{AC}$ could be determined by the expression of CK7, CK20, and MUC2; pancreaticobiliary AC is $\mathrm{CK} 7^{+} / \mathrm{CK} 20^{-} /$ MUC2 $2^{-}$, and intestinal $\mathrm{AC}$ is $\mathrm{CK} 7^{-} / \mathrm{CK} 20^{+} / \mathrm{MUC}^{+}[10]$. Zhou et al. classified $\mathrm{CK} 7^{-} / \mathrm{CK} 20^{+}$tumors as intestinal $\mathrm{AC}, \mathrm{CK}^{+} / \mathrm{CK} 20^{-}$tumors as pancreatobiliary AC, and tumors that are $\mathrm{CK}^{+} / \mathrm{CK} 20^{+}$or $\mathrm{CK} 7^{-} / \mathrm{CK} 20^{-}$as "other" [3]. However, there was no statistical difference in survival of patients with different CK7/CK20 subtypes [3] or with different CK20/MUC subtypes [11]. 
Osteopontin (OPN) is a secretory calcium-binding phosphorylated glycoprotein and plays an important role in bone metabolism. OPN is widely distributed in the urine, blood, gastrointestinal tract, pancreas, lungs and elsewhere. At the molecular level, OPN plays important roles in cellular adhesion and migration, tissue repair, and signal transduction and also in the invasion and metastasis of several cancers [12]. OPN is significantly associated with survival rate in several cancers and has value as a marker of clinical tumor progression [13,14]. In particular, low OPN levels were significantly associated with a favorable prognosis in patients with advanced non-small cell lung cancer [15], laryngeal and hypopharyngeal carcinomas [16], hepatocellular carcinoma [17], colorectal cancer [18], idiopathic pulmonary hypertension [19], upper urinary tract urothelial carcinoma [20], acute myeloid leukemia [21], oral squamous cell carcinoma [22], and endometrial cancer [23]. OPN may also be a suitable biomarker for overall survival and renal outcome of patients who are critically ill with acute kidney injury [24].

However, few studies have investigated the expression of OPN in patients with AC. Van Heek et al. reported higher OPN expression in the sera and tumors of AC patients than in the sera and duodenal samples of healthy controls [25]. Bloomston et al. reported that node-negative status and lack of OPN expression were associated with prolonged survival in patients with AC [26]. Hsu et al. reported that expression of OPN and the presence of tumor-associated macrophages in bulky AC were associated with tumor recurrence, and poorer disease-specific survival [27].

In the present study, we retrospectively analyzed the clinical data of 120 patients who were undergoing pancreaticoduodenectomy due to AC. We focused on the association of AC prognosis with the expression of CK7, CK20, and OPN.

\section{Patients and Methods \\ Patients}

From January 1, 1994 to December 30, 2008, patients undergoing pancreaticoduodenectomy due to $\mathrm{AC}$ were recruited from the Department of Hepatobiliary Surgery of the General Hospital of the Peoples Liberation Army (Beijing, China). The exclusion criteria were: (i) duodenal cancer, cancer of the lower bile duct, or cancer of the pancreas or any of these cancers involving the ampulla or duodenal papilla, based on pathological examination; (ii) uncertain origin of the cancer; (iii) previous focal resection of duodenal papillary cancer or AC; (iv) metastasis to other organs; and $(v)$ presence of concomitant heart disease, cerebrovascular disease, or pulmonary disease that made the patient ineligible for surgery. Follow-up examinations were performed at 3 months after surgery, once every 6 months for 3 years, and then once per year. These follow-up examinations included routine tests (liver and kidney function, blood electrolytes, routine blood test), tests for tumor markers, chest X-ray, and abdominal imaging by ultrasonography, CT, or MRI. The last follow-up was on January 31,2010 . Tumor stage and lymph node metastasis were evaluated according to Greene et al [28]. This study was approved by the hospital Institutional Review Board.

\section{Immunohistochemistry}

Carcinoma specimens were embedded in paraffin, cut consecutively into sections $(4 \mu \mathrm{m})$, and the streptavidin-peroxidase method was used for immunohistochemical visualization (UltraSensitive ${ }^{\mathrm{TM}}$ SP kit, Maximbio. Co. Ltd, Fuzhou, China). The primary antibodies were mouse antihuman CK7 or CK20 monoclonal antibodies and rabbit anti-human OPN polyclonal antibody (Lab Vision \& NeoMarkers, USA). The normal serum from non-immunized goat was used as a negative control of the primary antibody, and $\mathrm{CK}^{+} / \mathrm{CK}^{2} 0^{+} / \mathrm{OPN}^{+}$pancreatic carcinoma was used as a positive control.

Details for the determination of positive staining were previously provided[3]. In brief, cells positive for CK7, CK20, or OPN had brown or yellow-brown granules, mainly in the cytoplasm. Sections were evaluated by two independent and blinded pathologists. No staining or staining in fewer than $10 \%$ of cells was considered negative, and staining of $10 \%$ or more of cells was considered positive.

\section{Statistical analysis}

Results are expressed as means or medians with standard deviations, or counts and percentages. Survival analysis was analyzed by the Kaplan-Meier method and the log-rank test. Data were analyzed using SPSS 15.0 (SPSS, Inc., Chicago, IL, USA). All $p$-values were twosided and were considered significant if $p$ was less than 0.05 .

\section{Results}

\section{Patient characteristics}

A total of 120 patients ( 84 males, 36 females) met our inclusion criteria and received follow-up examinations. The mean age was $55.1 \pm 9.8$ years and the mean tumor diameter was $2.4 \pm 1.5 \mathrm{~cm}$. The 1-, 3- and 5-year survival rates were $94.8 \%, 78.7 \%$, and $68.0 \%$, respectively. The median survival time was $38 \pm 11.3$ months and the mean survival time was 53.9 months. A total of 51 patients (42.5\%) survived to the end of the follow-up period (January 31, 2010), 1 patient survived more than 10 years, and 2 patients survived more than 5 years. In addition to pancreaticoduodenectomy (given to all 
patients), 8 patients received chemotherapy. Among the 69 patients (57.5\%) who died in the follow-up period, 21 died within 5 years after surgery and 1 died 11 years after surgery.

\section{Survival of patients with different subtypes of AC}

Figure 1A-D shows representative immunohistochemical results of patients with intestinal $\mathrm{AC}\left(\mathrm{CK} 7^{-} / \mathrm{CK} 20^{+}\right)$, pancreatobiliary $\mathrm{AC}\left(\mathrm{CK} 7^{+} / \mathrm{CK} 20^{-}\right)$, and other subtype of

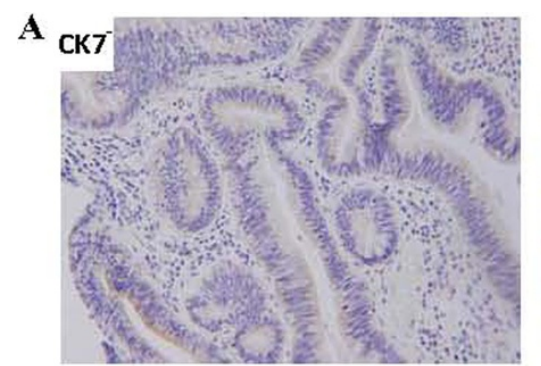

B

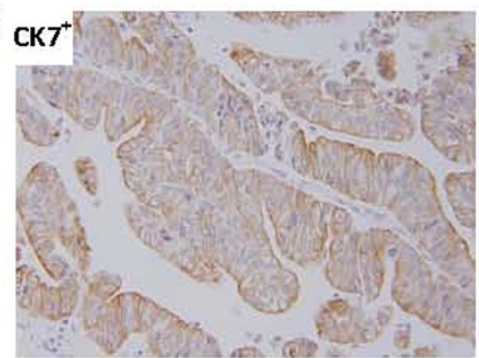

C

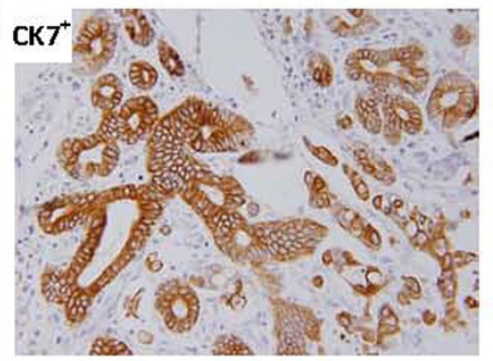

$\mathrm{D}_{\mathrm{CK} 7}$

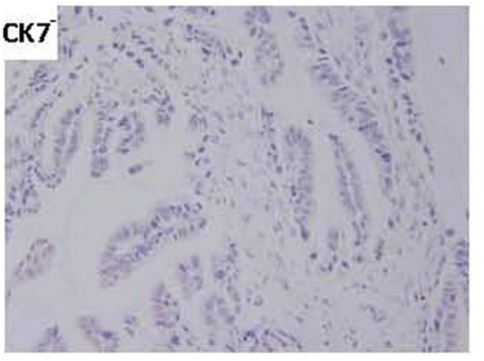

E OPN

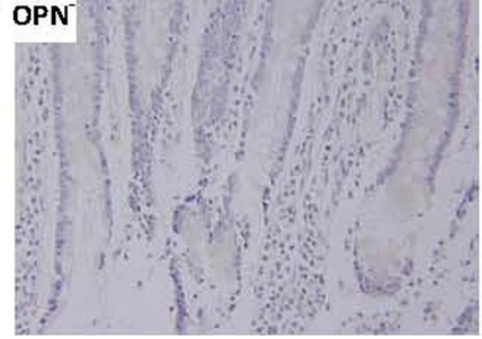

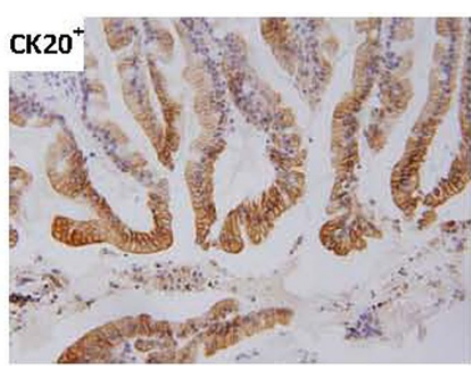
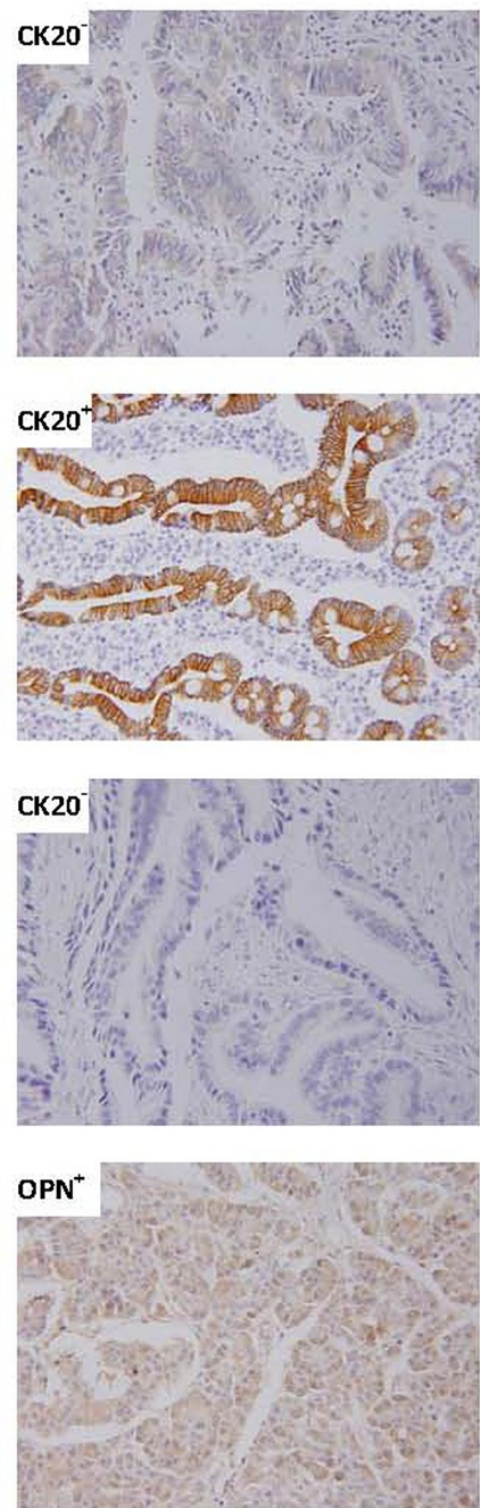

Figure 1 Representative immunohistochemical staining of ampullary cancer. A: intestinal type, CK7 $/ C K 20^{+}$; B: pancreatobiliary type, CK7 ${ }^{+} / \mathrm{CK}_{20}$; $\mathrm{C}$ : other type, $\left(\mathrm{C}: \mathrm{CK}^{+} / \mathrm{CK} 20^{+}\right)$; D: other type, $\left.\mathrm{CK} 7^{-} / \mathrm{CK} 20^{-}\right)$; E: positive and negative immunohistochemical staining for osteopontin. 
$\mathrm{AC}\left(\mathrm{CK}^{+} / \mathrm{CK} 20^{+}\right.$and $\left.\mathrm{CK} 7^{-} / \mathrm{CK} 20^{-}\right)$. Figure $1 \mathrm{E}$ shows representative positive and negative results for OPN staining.

Table 1 shows the survival times of AC patients stratified by immunohistochemical results, extent of tumor differentiation, amount of tumor invasion, and lymph node metastasis. None of the other associations were significant. $\mathrm{OPN}^{+}$patients had marginally longer survival time than $\mathrm{OPN}^{-}$patients $(p=0.062$; Figure $2 \mathrm{~A})$. The $1-, 3$, and 5 year survival rates were $84.3 \%, 55.3 \%$, and $0 \%$ for $\mathrm{OPN}^{+}$ patients and $91.8 \%, 68.4 \%$ and $7.2 \%$ for $\mathrm{OPN}^{-}$patients respectively.

Figure $2 \mathrm{~B}$ shows the survival times of patients with pancreatobiliary AC, intestinal AC, and other AC. Although pancreatobiliary AC was associated with slightly worse prognosis, a log-rank test indicated that this difference was only marginal ( $p=0.052$, Table 2 ). Figures $2 \mathrm{C}$ and $2 \mathrm{D}$ show the survival times of these three groups stratified by OPN expression. The results indicate that $\mathrm{OPN}^{-}$patients with different subtypes of AC had similar survival times $(p=0.75$, Table 2$)$. However, $\mathrm{OPN}^{+}$patients with different subtypes of AC had significantly different survival times $(p=0.017$, Table 2$)$. Specifically, $\mathrm{OPN}^{+}$patients with pancreatobiliary AC had worse prognosis than those with intestinal $\mathrm{AC}(p=0.041)$ and other subtype of $\mathrm{AC}$ ( $p=$ $0.010)$; the survival time of the patients with intestinal and other types had no difference. In addition, the survival time of patients with $\mathrm{OPN}^{+}$pancreatobiliary AC was

\begin{tabular}{llll}
$\begin{array}{l}\text { Table } 1 \text { Characteristics of ampullary carcinoma and } \\
\text { survival time of patients }\end{array}$ & N (\%) & $\begin{array}{l}\text { Survival } \\
\text { (months) }\end{array}$ & $\begin{array}{l}\text { time } \\
\text { P value }\end{array}$ \\
\hline Variable & & & \\
& & & \\
\hline Immunohistochemical Staining & $40(33.3)$ & $41.0 \pm 20.0$ & 0.166 \\
CK7 $^{-}$ & $80(66.7)$ & $36.0 \pm 3.7$ & \\
CK7 $^{+}$ & $35(39.2)$ & $31.0 \pm 24.3$ & 0.316 \\
CK20 $^{-}$ & $85(70.8)$ & $38.0 \pm 3.2$ & \\
CK20 $^{+}$ & $64(53.3)$ & $69.0 \pm 18.4$ & 0.062 \\
OPN $^{-}$ & $56(46.7)$ & $36.0 \pm 1.3$ & \\
OPN & \\
Total & $120(100)$ & $38 \pm 11.3$ & \\
Tumor Differentiation & & & 0.408 \\
Low & $34(28.3)$ & $35.0 \pm 3.4$ & \\
Medium & $37(30.8)$ & $36.0 \pm 15.7$ & \\
High & $49(40.8)$ & $41.0 \pm 18.9$ & \\
Tumor Invasion & & & 0.332 \\
T1 & $57(47.5)$ & $71.0 \pm 23.0$ & \\
T2 & $16(13.3)$ & $69.0 \pm 0.0$ & \\
T3 & $47(39.2)$ & $35.0 \pm 5.9$ & \\
Lymph node metastasis & & & 0.275 \\
No & $88(73.3)$ & $38.0 \pm 3.6$ & \\
Yes & $32(26.7)$ & $40.0 \pm 24.8$ & \\
\hline Sunva & & \\
\hline
\end{tabular}

Survival time is expressed as median \pm SD and $p$-values were calculated by the log-rank test. shorter than those with $\mathrm{OPN}^{-}$intestinal AC $(p=0.043)$, and other subtype of $\mathrm{AC}(p=0.002)$.

\section{Discussion}

Many previous studies have examined the expression of histological markers in the carcinomas of patients with ACs. For example, de Paiva Haddad et al. reported that MUC1, MUC2, and CDX2 provided the best agreement with histomorphological classification of AC [4]. However, their multivariate analysis indicated that neither histological classification nor immunohistochemical results were statistically independent predictors of poor prognosis. Moriya et al. reported that MUC1 and MUC2 expression was useful for classification of pancreatobiliary and intestinal AC, and that pancreatobiliary AC was associated with worse prognosis than intestinal AC [8]. Ehehalt et al. reported that immunohistochemical determination of HNF4 $\alpha$ expression distinguished different AC subtypes and that HNF4 $\alpha$ protein expression was an independent predictor of favorable prognosis [9]. Westgaard et al. classified ACs by expression of CK7, MUC4, and CDX2 [6]. They found only moderate agreement of the immunohistochemical and histomorphological classifications, and that expression of MUC1 and/or MUC4 was independently associated with poor prognosis. Santini et al. reported that MUC2 and MUC5 expression was not associated with prognosis of the patients with radically resected $\mathrm{AC}$ [7]. Clearly, it is difficult to completely reconcile these diverse and occasionally contradictory results, which have examined many markers in diverse patient populations.

Other researchers have reported immunohistochemical classification of AC based on expression of CK7 and CK20 $[3,10]$. Thus, in the present study we classified our AC patients as having pancreatobiliary $\mathrm{AC}\left(\mathrm{CK} 7^{+} / \mathrm{CK} 20^{-}\right.$, $20 \%)$, intestinal $\mathrm{AC}\left(\mathrm{CK}^{-} / \mathrm{CK} 20^{+}, 24.2 \%\right)$, or other subtype of $\mathrm{AC}\left(\mathrm{CK}^{+} / \mathrm{CK} 20^{+}\right.$or $\left.\mathrm{CK}^{-} / \mathrm{CK} 20^{-}, 55.8 \%\right)$. Thus, the majority of our Chinese patients had other subtype of $\mathrm{AC}$, in contrast to Kimura et al. [2], who studied Japanese patients, and Zhou et al. [3] who studied German patients and reported that pancreatobiliary AC was the most common subtype. This difference might be due to population differences and/or to the different reactivity thresholds used in the immunohistochemical classification [29]. Our survival analysis indicated no significant differences in survival among patients with the different subtypes of AC, consistent with the report of Zhou et al. [3]. Taken together, these findings suggest the immunohistologic subtype of $\mathrm{AC}$ alone has limited value in determination of the prognosis.

Previous research has indicated that OPN expression is significantly associated with poor survival of patients with several forms of cancer $[13,14]$. It has also been reported that elevated OPN expression in AC patients 


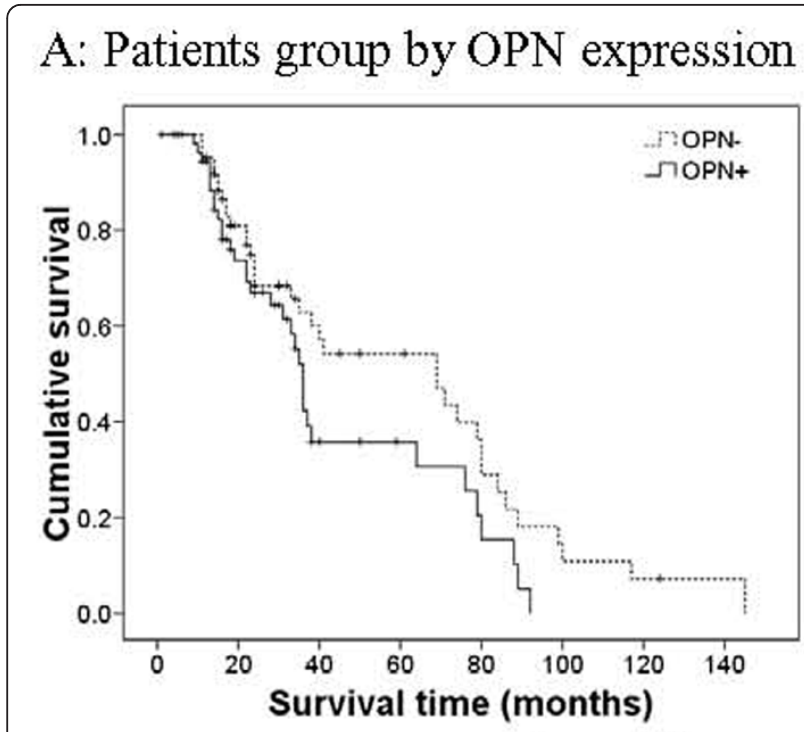

B: Patients group by types
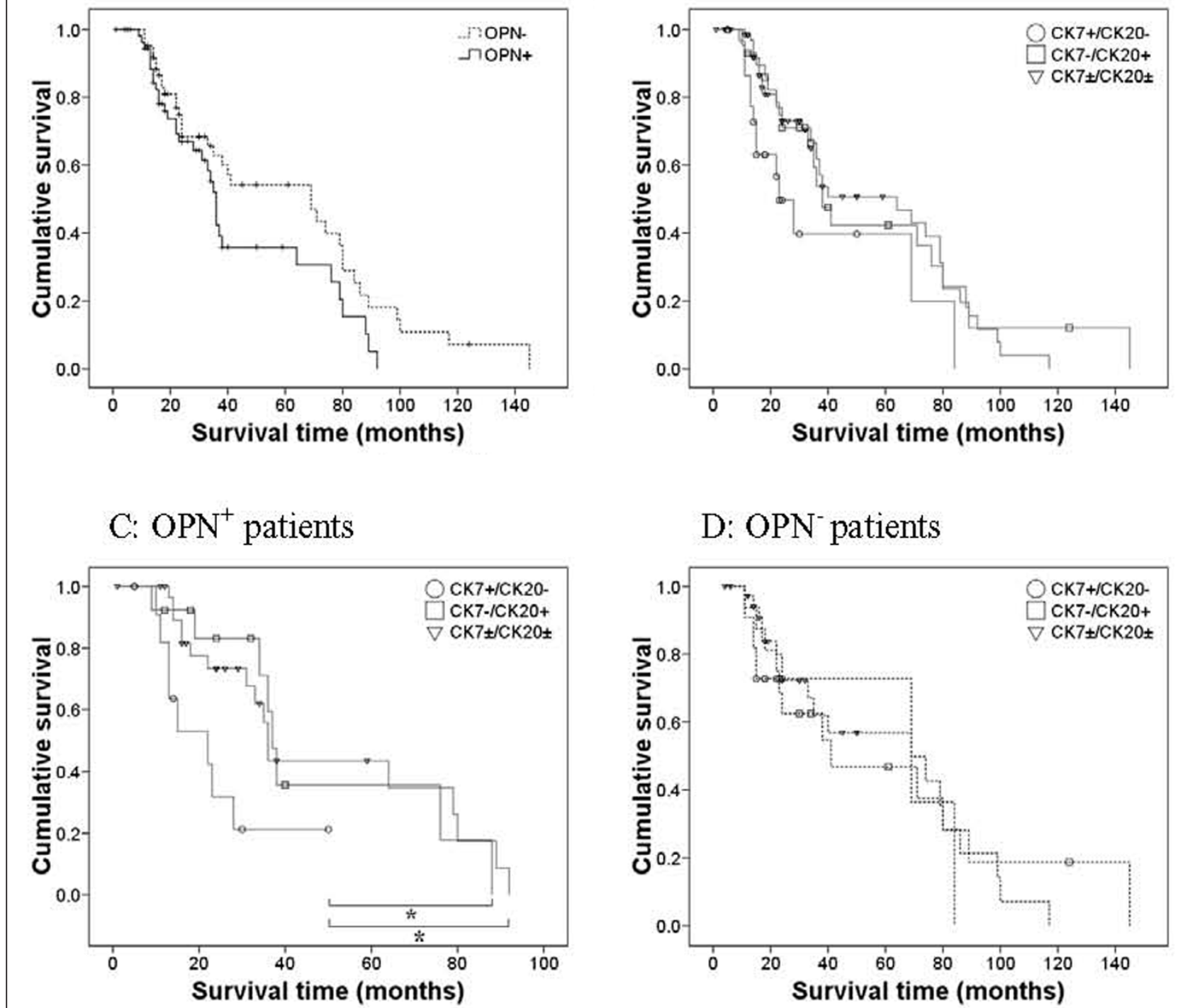

\section{D: OPN patients}

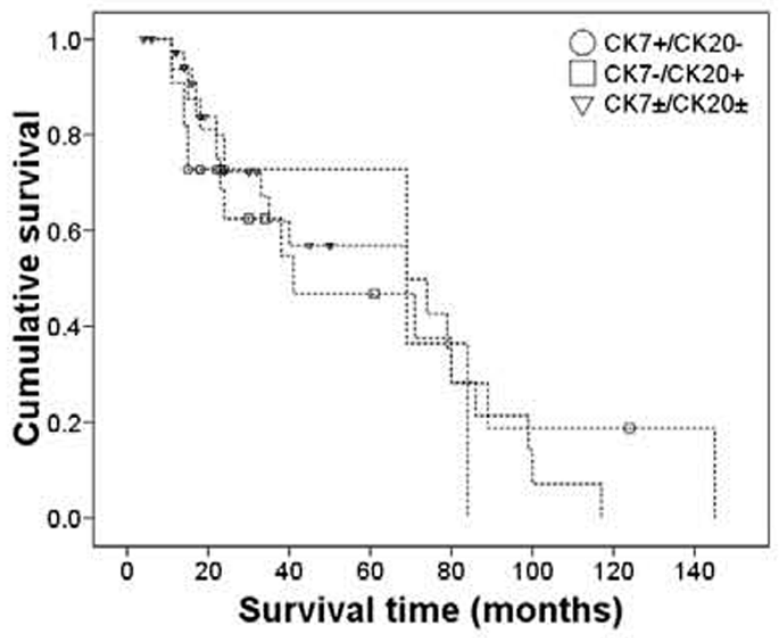

Figure 2 Kaplan-Meier survival curves of patients with different immunohistochemical types of ampullary cancer and with positive or negative expression of osteopontin. ${ }^{*} p<0.05$ by log-rank test.

Table 2 Expression of OPN and survival time of patients with different subtypes of ampullary carcinoma (AC)

\begin{tabular}{lllll}
\hline \multicolumn{4}{c}{ Survival time in months (number of patients) } \\
& Pancreatobiliary & Intestinal & Other & p value $^{1}$ \\
\hline Total & $23 \pm 4.2(24)$ & $38 \pm 2.8(29)$ & $64 \pm 16.8(67)$ & 0.052 \\
OPN $^{-}$ & $69 \pm 39.5(11)$ & $41 \pm 24.8(16)$ & $69 \pm 26.8(37)$ & 0.750 \\
OPN $^{+}$ & $22 \pm 6.6(13)^{*}$ & $37 \pm 1.4(13)$ & $36 \pm 0.9(30)$ & 0.017 \\
p value $^{2}$ & 0.085 & 0.509 & 0.263 &
\end{tabular}

Survival time is expressed as median \pm SD. ${ }^{1} p$-value for comparison of the 3 types; ${ }^{2} p$-value for comparison of the $\mathrm{OPN}^{+}$and $\mathrm{OPN}^{-}$groups. ${ }^{*} p=0.041$ and $p=0.010$ for comparison with the intestinal type and other type $\mathrm{OPN}^{+} \mathrm{AC}$ respectively. There was no difference between intestinal $A C$ and other type of AC $(p=0.907)$ predicts poor disease-specific survival [25-27]. However, when we pooled all AC subtypes, we found that survival time of $\mathrm{OPN}^{-}$and $\mathrm{OPN}^{+}$patients had no significant difference. This is consistent with the results of Matsuzaki et al., who reported that OPN expression in AC patients was not associated with survival rate, although OPN expression in the carcinoma was higher than in adjacent normal tissues [30].

Our further analysis indicated that the subtype of AC (intestinal, pancreatobiliary, or other) had no significant effect on survival of patients with $\mathrm{OPN}^{-}$carcinomas. However, for patients with $\mathrm{OPN}^{+}$carcinomas, those with intestinal AC or other subtype of AC had significantly 
better survival than those with pancreatobiliary AC. Thus, OPN expression appears to affect the biological behavior of $\mathrm{AC}$, and this effect depends on the anatomi$\mathrm{cal}$ origin of the tumor. These results indicate that determination of the prognosis of patients with AC should consider OPN expression.

Previous studies have reported interactions of OPN with other proteins. For example, in situ proximity ligation analysis indicated a molecular interaction of OPN and CD44 and that elevated expression of these proteins were associated with increased mitosis and significantly enhanced gastrointestinal stromal tumor cell proliferation in vitro [31]. Yang et al. reported that OPN combined with CD44 was a promising independent predictor of tumor recurrence and survival in patients with hepatocellular carcinoma [32]. OPN combined with CDX2 appears to predict survival of advanced gastric cancer patients, and CDX2 may be a transcription factor that modulates the expression of osteopontin [33]. Our results support previous reports which suggest that OPN has a role in the pathogenesis of AC [25-27]. However, a limitation of our study is that patients were enrolled retrospectively, and we did not include histomorphological classification of patients or immunochemical determination based on other factors including CDX2 and mucins. Clearly, the potential interaction of OPN, CK7, CDX2, mucins and other factors and the role of these in the pathogenesis of $\mathrm{AC}$ warrant further studies.

\section{Conclusions}

In conclusion, our results indicate that it is difficult to determine prognosis of patients with AC based solely on immunohistochemical classification that considers CK7 and CK20 status. However, the additional consideration of OPN status allows determination of prognosis. Our results also suggest that OPN plays a role in the pathogenesis of $\mathrm{AC}$, but its mechanisms and relationship with CK7 and CK20 warrant further studies.

\section{Abbreviations \\ AC: ampullary cancer; OPN: osteopontin; CK7: Cytokeratin 7; CK20: Cytokeratin 20}

\section{Acknowledgements}

None.

\section{Authors' contributions}

XQZ carried out the study design, defined the intellectual content, participated in the literature research and manuscript preparation, analyzed data, and edited the manuscript. JHD do guarantor of integrity of the entire study, carried out the study concepts, and reviewed the manuscript. WZZ carried out the clinical studies, and acquired data. ZL carried out the experimental studies, and did statistical analysis. All authors read and approved the final manuscript.

\section{Competing interests}

The authors declare that they have no competing interests.
Received: 30 August 2011 Accepted: 13 October 2011

Published: 13 October 2011

\section{References}

1. Howe JR, Klimstra DS, Moccia RD, Conlon KC, Brennan MF: Factors predictive of survival in ampullary carcinoma. Ann Surg 1998, 228:87-94.

2. Kimura W, Futakawa N, Yamagata S, Wada Y, Kuroda A, Muto T, Esaki Y: Different clinicopathologic findings in two histologic types of carcinoma of papilla of Vater. Jpn J Cancer Res 1994, 85:161-166.

3. Zhou H, Schaefer N, Wolff M, Fischer HP: Carcinoma of the Ampulla of Vater: Comparative Histologic/Immunohistochemical Classification and Follow-up. Am J Surg Pathol 2004, 28:875-882.

4. de Paiva Haddad LB, Patzina RA, Penteado S, Montagnini AL, da Cunha JE, Machado MC, Jukemura J: Lymph node involvement and not the histophatologic subtype is correlated with outcome after resection of adenocarcinoma of the ampulla of vater. J Gastrointest Surg 2010, 14:719-728.

5. Le Pessot F, Ranty ML, Hellot MF, Lemoine F, Teniere P, Testart J, Metayer J: Cytokeratins 7 and 20 immunohistochemistry in ampullary carcinomas. Ann Pathol 2004, 24:312-318.

6. Westgaard A, Schjolberg AR, Cvancarova M, Eide TJ, Clausen OP, Gladhaug IP: Differentiation markers in pancreatic head adenocarcinomas: MUC1 and MUC4 expression indicates poor prognosis in pancreatobiliary differentiated tumours. Histopathology 2009, 54:337-347.

7. Santini $\mathrm{D}$, Baldi $\mathrm{A}$, Vincenzi B, Mellone $\mathrm{P}$, Campioni M, Antinori A, Borzomati D, Coppola R, Magistrelli P, Tonini G: Mucin 2 (MUC2) and mucin 5 (MUC5) expression is not associated with prognosis in patients with radically resected ampullary carcinoma. J Clin Pathol 2007, 60:1069-1070.

8. Moriya T, Kimura W, Hirai I, Takasu N, Mizutani M: Expression of MUC1 and MUC2 in Ampullary Cancer. Int I Surg Pathol 2011, 19:441-447.

9. Ehehalt F, Rummele P, Kersting S, Lang-Schwarz C, Ruckert F, Hartmann A, Dietmaier W, Terracciano L, Aust DE, Jahnke B, Saeger HD, Pilarsky C, Grutzmann R: Hepatocyte Nuclear Factor (HNF) 4alpha Expression Distinguishes Ampullary Cancer Subtypes and Prognosis After Resection. Ann Surg 2011, 254:302-310.

10. Fischer HP, Zhou H: Pathogenesis of carcinoma of the papilla of Vater. $J$ Hepatobiliary Pancreat Surg 2004, 11:301-309.

11. Kawabata Y, Tanaka T, Nishisaka T, Inao T, Nishi T, Yano S: Cytokeratin 20 (CK20) and apomucin 1 (MUC1) expression in ampullary carcinoma: Correlation with tumor progression and prognosis. Diagn Pathol 2010 $5: 75$.

12. Goparaju CM, Pass HI, Blasberg JD, Hirsch N, Donington JS: Functional heterogeneity of osteopontin isoforms in non-small cell lung cancer. J Thorac Oncol 2010, 5:1516-1523.

13. Coppola D, Szabo M, Boulware D, Muraca P, Alsarraj M, Chambers AF, Yeatman TJ: Correlation of osteopontin protein expression and pathological stage across a wide variety of tumor histologies. Clin Cancer Res 2004, 10:184-190

14. Lorenzen JM, Nickel N, Kramer R, Golpon H, Westerkamp V, Olsson KM, Haller H, Hoeper MM: Osteopontin in patients with idiopathic pulmonary hypertension. Chest 2011, 139:1010-1017.

15. Isa S, Kawaguchi T, Teramukai S, Minato K, Ohsaki Y, Shibata K, Yonei T, Hayashibara K, Fukushima M, Kawahara M, Furuse K, Mack PC: Serum osteopontin levels are highly prognostic for survival in advanced nonsmall cell lung cancer: results from JMTO LC 0004. J Thorac Oncol 2009, 4:1104-1110.

16. Li Y, Li L, Wang JT, Kan X, Lu JG: Elevated content of osteopontin in plasma and tumor tissues of patients with laryngeal and hypopharyngeal carcinoma associated with metastasis and prognosis. Med Oncol 2011, 28:1-6.

17. Sieghart W, Wang X, Schmid K, Pinter M, Konig F, Bodingbauer M, Wrba F Rasoul-Rockenschaub S, Peck-Radosavljevic M: Osteopontin expression predicts overall survival after liver transplantation for hepatocellular carcinoma in patients beyond the Milan criteria. J Hepatol 2011, 54:89-97.

18. Likui W, Hong W, Shuwen Z: Clinical significance of the upregulated osteopontin mRNA expression in human colorectal cancer. J Gastrointest Surg 2010, 14:74-81.

19. Weber GF, Lett GS, Haubein NC: Osteopontin is a marker for cancer aggressiveness and patient survival. Br J Cancer 2010, 103:861-869. 
20. Ke HL, Chang LL, Yang SF, Lin HH, Li CC, Wu DC, Wu WJ: Osteopontin overexpression predicts poor prognosis of upper urinary tract urothelial carcinoma. Urol Oncol 2009.

21. Powell JA, Thomas D, Barry EF, Kok CH, McClure BJ, Tsykin A, To LB, Brown A, Lewis ID, Herbert K, Goodall GJ, Speed TP, Asou N, Jacob B, Osato M, Haylock DN, Nilsson SK, D'Andrea RJ, Lopez AF, Guthridge MA: Expression profiling of a hemopoietic cell survival transcriptome implicates osteopontin as a functional prognostic factor in AML. Blood 2009, 114:4859-4870.

22. Chien CY, Su CY, Chuang HC, Fang FM, Huang HY, Chen CH, Chen CM, Huang CC: Comprehensive study on the prognostic role of osteopontin expression in oral squamous cell carcinoma. Oral Oncol 2009, 45:798-802.

23. Cho H, Kang ES, Kim YT, Kim JH: Diagnostic and prognostic impact of osteopontin expression in endometrial cancer. Cancer Invest 2009, 27:313-323.

24. Lorenzen JM, Hafer C, Faulhaber-Walter R, Kumpers P, Kielstein JT, Haller $H_{\text {, }}$ Fliser D: Osteopontin predicts survival in critically ill patients with acute kidney injury. Nephrol Dial Transplant 2011, 26:531-537.

25. Van Heek NT, Maitra A, Koopmann J, Fedarko N, Jain A, Rahman A, lacobuzio-Donahue CA, Adsay V, Ashfaq R, Yeo CJ, Cameron JL, Offerhaus JA, Hruban RH, Berg KD, Goggins M: Gene expression profiling identifies markers of ampullary adenocarcinoma. Cancer Biol Ther 2004, 3:651-656.

26. Bloomston M, Ellison EC, Muscarella P, Al-Saif O, Martin EW, Melvin WS, Frankel WL: Stromal osteonectin overexpression is associated with poor outcome in patients with ampullary cancer. Ann Surg Oncol 2007, 14:211-217.

27. Hsu HP, Shan YS, Lai MD, Lin PW: Osteopontin-positive infiltrating tumorassociated macrophages in bulky ampullary cancer predict survival. Cancer Biol Ther 2010, 10:144-154.

28. Greene FL, Page DL, Fleming ID, Fritz A, Balch CM, Haller DG, Morrow M: AJCC Cancer Staging Manual (6th Edition). 6 edition. New York, NY: Springer; 2002.

29. Goldstein NS, Bassi D: Cytokeratins 7, 17, and 20 reactivity in pancreatic and ampulla of vater adenocarcinomas. Percentage of positivity and distribution is affected by the cut-point threshold. Am J Clin Pathol 2001, 115:695-702.

30. Matsuzaki H, Shima K, Muramatsu T, Ro Y, Hashimoto S, Shibahara T, Shimono M: Osteopontin as biomarker in early invasion by squamous cell carcinoma in tongue. J Oral Pathol Med 2007, 36:30-34.

31. Hsu KH, Tsai HW, Lin PW, Hsu YS, Shan YS, Lu PJ: Osteopontin expression is an independent adverse prognostic factor in resectable gastrointestinal stromal tumor and its interaction with CD44 promotes tumor proliferation. Ann Surg Oncol 2010, 17:3043-3052.

32. Yang GH, Fan J, Xu Y, Qiu SJ, Yang XR, Shi GM, Wu B, Dai Z, Liu YK, Tang ZY, Zhou J: Osteopontin combined with CD44, a novel prognostic biomarker for patients with hepatocellular carcinoma undergoing curative resection. Oncologist 2008, 13:1155-1165.

33. Zhang X, Tsukamoto T, Mizoshita T, Ban H, Suzuki H, Toyoda T, Tatematsu M: Expression of osteopontin and CDX2: indications of phenotypes and prognosis in advanced gastric cancer. Oncol Rep 2009, 21:609-613.

doi:10.1186/1746-1596-6-98

Cite this article as: Zhao et al:. Prognosis of ampullary cancer based on immunohistochemical type and expression of osteopontin. Diagnostic Pathology 2011 6:98.

\section{Submit your next manuscript to BioMed Central and take full advantage of:}

- Convenient online submission

- Thorough peer review

- No space constraints or color figure charges

- Immediate publication on acceptance

- Inclusion in PubMed, CAS, Scopus and Google Scholar

- Research which is freely available for redistribution

Submit your manuscript at www.biomedcentral.com/submit
Biomed Central 